This paper is motivated by a desire to deal with the problematic aspects of technical development. To achieve this, we need a new approach to the analysis of socio-technical change. In this paper we develop such an approach, called the 'Socio-Technical Networks' (STN) approach. The basic concepts of this approach, and its application, are illustrated in a case study of the development of the European Fighter Aircraft. In the final section, some suggestions are made as to how the STN approach can help

to induce technological change in a direction that is considered desirable from a broader societal perspective, and how the approach should be further elaborated.

\title{
Socio-Technical Networks: How a Technology Studies Approach May Help to Solve Problems Related to Technical Change
}

\section{Boelie Elzen, Bert Enserink and Wim A. Smit}

Technological development is typically seen as one of the main sources, if not the main source, of human prosperity. Especially over the past decades, however, awareness has grown that technological development can cause major societal problems at the same time: environmental degradation is one of the most widely acknowledged examples. This raises the question whether technological development cannot be 'directed' in some sense so that it causes less societal problems and/or, if problems have already emerged, whether it cannot be redirected to solve these problems without leading to new trouble.

Various branches of science (and of policy) are already dealing with this type of question: the environmental sciences are an example. And fields with a more general research agenda, like science and technology policy studies, often take societal issues into account. These fields have made various contributions towards (partial) solutions of such problems but, in view of the

Social Studies of Science (SAGE, London, Thousand Oaks, CA and New Delhi), Vol. 26 (1996), 95-141 
problems faced, their contributions are rather modest. One of the main reasons for this, we think, is that these fields insufficiently acknowledge the heterogeneity of processes of technical change processes which involve a wide range of factors, including technological, political, economic, social and so on. Most fields we have mentioned explicitly stress one or two of these aspects, thus neglecting the heterogeneity of the whole process. Accepting this heterogeneity, of course, is one of the starting points of the field of technology studies.

This then raises the question whether technology studies has something to contribute to solving problems of this kind. To be more precise we would phrase the question: 'What can technology studies contribute towards the guidance of technological development on the basis of societal priorities?'. Phrasing the question this way immediately raises a number of new questions. Who is 'guiding'? What does it entail? What are 'societal priorities'? Who will define them? Has not technology studies convincingly demonstrated that processes of socio-technical development are very heterogeneous, and that there is no 'central point' from which they are 'directed'? These are important questions which, we acknowledge, cannot be answered easily. In this paper, we will not try to answer them. We do want to indicate briefly, though, why we phrase the question this way.

We use the phrase 'guidance' to emphasize that the existing dynamics of socio-technical change cannot be 'overruled' from some sort of outside perspective. The existing dynamics should be taken as a starting point: the question then becomes whether relatively minor new initiatives can be taken that would trigger processes leading eventually to the solution of important problems.

The second important element of the question is the phrase 'societal priorities'. This phrase is rather vague, but we have used it explicitly to leave open the question of how these priorities should be defined. One way to achieve this is to let a broader range of actors and considerations play a role in early stages of technological development, as has been suggested by a number of researchers in the field of 'Constructive Technology Assessment'. 1 Analysts of technological development could explore possibilities to implement 'societal priorities' on the basis of 'research in action' - that is, by making suggestions to various actors who are attempting to solve concrete problems, and by analyzing why these 
suggestions are (or are not) picked up, and how this affects the subsequent development process. ${ }^{2}$ Using the phrase 'societal priorities' also refers to attempts to bring more reflexivity into technology development processes.

Although we cannot operationalize the phrase 'societal priorities' at this point, by phrasing the question 'what can technology studies contribute towards the guidance of technological development on the basis of societal priorities?', we can still argue that the field of technology studies has important contributions to make. This is especially true in situations where there is wide consensus that there is a problem, but where it appears difficult to solve it because there are so many actors and other issues involved. In such a case, a technology studies approach should analyze the 'existing situation and its dynamics', and so present it that it is possible to evaluate what the likely effects of 'new inputs' into the process are. If new inputs can be found that (1) can be brought into the process; (2) are not likely to be counteracted by crucial actors; and (3) promise to solve (part of) the problem, we would have made an important step in the desired direction.

Presented in this way, the problem of 'guiding technological development on the basis of societal priorities' is broken down into two parts. The first is to analyze 'the existing situation and its dynamics'; and the second is to evaluate the likely effect of possible new inputs into the process - and, eventually, to implement these.

In this paper we will only deal with the first step, for two reasons. The first is that this is where the main contribution of technology studies lies. In the second step, a wider range of issues starts playing a role that would also require insights from other fields of enquiry. The second reason is that the first step is already rather demanding. Dealing with both steps in a single paper would then lack the necessary depth of analysis to be convincing. ${ }^{3}$ Still, to be able to make the first step, we need to be explicit that our goal is also to make the second. This is because the ambition to contribute towards the 'guidance of technological development on the basis of societal priorities' implies that a technology studies approach has to fulfil specific requirements. It is for this reason that we do not see our approach as a just another framework of analysis' of technological development: we see it explicitly as a stepping stone towards solving problems related to technical change, which we seek to elaborate in our future work. 
In the next section, we start by formulating five requirements that a technology studies approach should fulfil if it is to be a potentially useful source of 'guidance' in our sense. Subsequently we will (very briefly) discuss existing technology studies approaches, and conclude that we need a new approach in order to fulfil all five of these requirements. In the next section we sketch the contours of such a new approach, which we call the 'sociotechnical network' (STN) approach. ${ }^{4}$ The remaining part of the paper is primarily devoted to elaborating the STN approach on the basis of a case study of the development of the European Fighter Aircraft (EFA). We will conclude with a brief discussion on some implications of the STN approach for possibilities of the kind of 'guidance' we have in mind.

We have chosen our case study from the domain of military technology because this paper is part of a more encompassing research programme, the explicit aim of which is to seek ways to influence the development and implementation of new weapon systems from a broader perspective than military considerations for example, by also considering the effect new weapons may have on (im-)possibilities for arms control. ${ }^{5}$ However, based on other work currently in progress, we think that the approach we develop below is also useful for other domains of technological development. ${ }^{6}$ We will return to this issue in the concluding section.

\section{A Framework of Analysis}

\section{Five Requirements}

In technology studies various approaches are used, each of which highlights different aspects of the processes of socio-technical change. When seeking to influence technological development on the basis of societal priorities, each of these approaches has rendered valuable insights that should be taken into account. This has led us to formulate the following five requirements for the type of approach we need:

1. The framework should enable tracing the factors that 'guide' various actors in their acts - both in their interactions with other actors, and with the technology we are interested in. Special attention should be paid to factors that work as a heuristic to decide what technological course to take, what technology to 
develop, procure, use and so on. Without knowledge of such factors we cannot evaluate the effects of possible new inputs in the development process - how these are likely to be picked up, built further upon, counteracted and the like.

2. The framework should enable us to analyze these factors in a dynamic way, acknowledging that they can be subject to change. Actors are not static in the way they make their evaluations, new actors may appear, and existing actors may vanish from the scene.

3. The framework should acknowledge the heterogeneity of processes of socio-technical change, in the sense that it allows that both the technological and the social aspects are subject to continuous change. As is stressed in the actor-network approach, we acknowledge that everything can change in principle.

4. On the other hand, as various system approaches also stress, ${ }^{8}$ it is clear that certain stable patterns can be recognized in sociotechnical development. In the case of the European Fighter Aircraft, for instance, various lasting and obdurate relationships between industry, the military and politicians have developed that co-determine the shaping of the next generations of weapons. The framework should allow such 'structural' factors to be identified, and thus be able to cope with a certain degree of continuity in processes of socio-technical change.

5. The social construction of technology (SCOT) approach stresses that different actors (or, rather, different social groups) attribute different meanings to an artefact: this is denoted by the phrase 'interpretative flexibility'. ${ }^{9}$ For instance, to the military, a fighter is primarily for attacking the enemy; to an electronics firm, it is primarily a box of electronics that allows the company to make a profit. The framework should, therefore, account for the different meanings that different actors attribute to the technology in question.

\section{Existing Frameworks: Problems for Our Purposes}

Given that we lean heavily on insights developed in the field of technology studies, the obvious thing for us to do would be to pick the approach most suited to our purposes, and then to elaborate that one further. However, each of the available approaches has characteristics that would make that exercise very problematic. Therefore, we have developed a new framework in which (as we 
discuss in the next section) we borrow some concepts from existing approaches. This is not the place for an elaborate discussion, but we will briefly mention some of the problems we face when we try to adapt those approaches to our purposes.

The social construction of technology (SCOT) approach is very interesting because it sheds light on how actors interact with technology, and in what direction they pursue technological change (requirement 1 above). It sees actors as members of a socalled 'relevant social group', all members having in common that a particular artefact has a specific meaning for them. Furthermore, the notion of 'interpretative flexibility' (requirement 5) is at the very heart of this approach. However, problems arise when we look at requirement 2 , which would imply that the meaning a relevant social group attributes to a technological artefact can change, if only to a minor extent. Thus relevant social groups (or, to be more precise, 'technological frames') ${ }^{10}$ should be analyzed dynamically. The SCOT approach does not offer us any tools to do so. Requirement 4 also raises problems. It is not only membership of a relevant social group that determines how an actor interacts with the artefact, but also existing patterns of interactions in which other actors play important roles. We will return to this point later, when we discuss the role of what we have called 'pre-existing networks'. ${ }^{11}$

The actor-network approach stresses the freedom actors have in their interactions with other actors (requirement 3 ). It does so, however, by strongly arguing against the role of stable, systemic factors (requirement 4). Callon has sought to account for this in a further elaboration of the approach, which he calls technoeconomic networks. He has developed a conceptual vocabulary that should enable the analyst to investigate, in a concrete situation, the extent to which technological change within a network exhibits more or less fixed patterns. ${ }^{12}$ For our purposes, however, techno-economic networks are also problematic. The approach offers few conceptual tools to help us understand how actors come to have characteristic ways of interacting with technology. All Callon states is that actors can 'translate' other actors and 'intermediaries' (both of which can refer to technological artefacts). We then get into trouble with requirement 1 (being able to trace factors that guide the actors).

In contrast to the actor-network approach, system approaches stress the systemic character of socio-technical change (require- 
ment 4). Typically, these approaches have offered us case histories of the development of technologies that have a wide impact in society and/or are what are often called 'large technical systems'. The problem for us, however, is that they do not provide a specified set of concepts to help us analyze how the various actors interact with the technology, how they evaluate it and in what direction they pursue technological change (requirement 1 above). Thus, they cannot be adapted easily for our purposes either.

\section{Towards a New Framework}

Summarizing, all the approaches have some features that are relevant to us, but all have problems as well. We therefore decided to develop our own approach to the analysis of processes of sociotechnical change, 'borrowing' and combining some of the concepts used in existing approaches.

\section{Socio-Technical Networks}

\section{Major Characteristics}

We will try to account for the heterogeneous set of requirements listed in the previous section, using the notion of a 'network'. These networks will be defined with respect to the specific technology (or group of technologies) the analyst is interested in. In our case study, we will therefore speak of the European Fighter Aircraft (EFA) network.

In our approach, the nodes in a network are considered to be either individual human actors or (representatives of) groups of human actors. This contrasts with the actor-network and technoeconomic networks approaches, where technologies can also be actors. (We will return to this point below.) A network is further characterized by the interactions between the actors, which can be of a very heterogeneous nature. Actors may exchange speech, documents, money, artefacts, and the like. What we are interested in are those interactions that have some relationship with the development of the artefact. Furthermore, actors can have a 'private interaction' with the artefact - for example, by developing or using it. Thus our networks describe the interactions between social entities, as well as those between social entities and 
artefacts. For that reason we call our networks 'socio-technical networks' (STNs), since they allow us to study the interrelations between social and technical developments, emphasizing that the two always go together.

In the following sub-sections we will briefly discuss some important elements of STNs - notably, actors, 'intermediaries' and technology. Subsequently, we will address some important characteristics of the dynamics of STNs - notably, 'resilience' and interactions between STNs and their 'environment'.

\section{Actors}

In our approach, the actors (= the nodes) of the network are either human individuals or groups of humans (for example, organizations). Which is most fruitful depends on the phenomena we are interested in, and on whether we have good empirical reasons to see a group of humans as a single actor - that is, as an actor who is seen as such by other actors in our network, and who operates as such in the interactions we focus our analysis on (for instance, defines situations and problems in one way; speaks with one voice; and so on).

The links between the nodes denote the interactions between the actors, interactions in which technology plays an important role. In a sense, our networks can be seen as essentially 'social' networks, since they display the relationships between social entities. The difference with traditional social network analysis, ${ }^{13}$ however, is that we very explicitly pay attention to the role of technology in these interactions (while we also look at the interactions between actors and technology).

In contrast to the actor-network approach, we do not see technology as an 'actor' in STNs. The main reason is that the human and the non-human actors do have different characteristics that are relevant for what we seek to achieve: we look for possibilities to guide technological change by influencing the way humans interact with technology and with each other. ${ }^{14}$

\section{Intermediaries}

In STNs, the links between the nodes denote the interactions between the actors. In these interactions, something goes from 
one actor to the other (and vice versa). Following Callon, we will call this 'something' an intermediary. An intermediary, to paraphrase Callon, is anything that passes from one actor to another, and which constitutes the form and the substance of the relation set up between them - scientific papers, software, technological artefacts, instruments, contracts, money and so on. ${ }^{15}$

Focusing on the actor, we see that $\mathrm{s} / \mathrm{he}$ receives a variety of intermediaries, while sending out a variety of others. Actors can therefore be seen as processors of intermediaries. Actors recombine incoming intermediaries, and send out their own. ${ }^{16}$ What characterizes the actors are the characteristics of this recombination process. Some examples relevant to our case are:

- Engineers recombine, for instance, (scientific) papers, money, instruments, raw materials, artefacts, and so on, into other artefacts, patent applications, and the like.

- Military recombine, for instance, information, money, soldiers and artefacts into military strategy, training programmes, organized units of soldiers, artefacts (weapons), and so on.

- 'Politicians' recombine, for instance, taxpayers' money and a host of information into money allocations for R\&D, social security programmes, and the like.

By focusing on these recombination processes, our approach satisfies the first two requirements stated above.

\section{Technology}

To start with, technology can go from one actor to another (for example, in the process of selling/buying), and thus be an intermediary. Following the SCOT approach, we acknowledge the 'interpretative flexibility' of the artefact. This implies that, for instance, the relevant characteristics of an artefact sold by a weapons producer may differ from those considered relevant by the armed services (requirement 5). Analytically, this implies that the artefact has changed in the process of exchange between actors. ${ }^{17}$ The way in which we will analyze these developments is to localize an actor-specific version of the artefact (rather than the 
artefact) with each of the actors in the network - a version that reflects the relevant characteristics of the artefact to that specific actor. This, of course, is analogous to the way artefacts are treated in the SCOT approach. ${ }^{18}$

Thus STNs could be visualized as follows: the actors constitute the nodes of the network; below each actor, and connected to that actor only, is her/his version of the artefact; and between the actors are the links that reflect the exchange of intermediaries (including technology). Actors recombine incoming intermediaries, process them and subsequently send out new intermediaries. Actors are characterized by the nature of this recombination process.

\section{Stable Patterns of Interaction - Resilience}

Although the content of the intermediaries exchanged between actors (for instance, the content of documents or the types of artefacts) changes continuously, at a higher level of abstraction patterns can often be discerned that remain unaltered over longer periods of time (for example, in our case study, the way weapons are designed, manufactured, sold, used and scrapped). This makes it possible to recognize networks with a certain degree of stability. Thus, stable patterns of interaction may develop between governments and military establishments; between companies and members of parliament; and so on.

This stability is an important characteristic of STNs. ${ }^{19}$ The reason for distinguishing between more and less stable patterns, and calling the former 'networks', is that stabilized patterns of interaction play a role different from non-stabilized ones. The main distinction is that actors do not usually act in a way that might jeopardize existing patterns of interaction. And if they still do, other actors in the network often react in such a way as to counter the destabilizing 'threat', and bring everything back to order again. It is for this reason that we claim that STNs are characterized by a certain resilience. ${ }^{20}$

The background for the emergence of resilience is that actors are active as processors of intermediaries. And, overall, the various actors behave in such a way that they tend to perpetuate existing patterns of interaction. This is the result of three different mechanisms that are operating at the same time, notably: 
1. Actors cannot randomly do what they want but are (partly) dependent upon incoming intermediaries. In this way, the network 'directly' limits an actor's 'acting space'.

2 . Even when constrained by incoming intermediaries, actors still have a wide variety of options of how to process them. To be able to do that in a potentially successful way, actors make their own evaluation of what intermediaries will be picked up by what actors. They have their expectations ${ }^{21}$ of what will or will not 'sell' and it is on these expectations that they base their decisions on what intermediaries to assemble and send on. Because of their experience in past interactions, actors can (and tend to) tune their acts towards what is considered relevant by other actors. This can be seen as a form of 'self-constraint' by the actors.

3. Still, actors can be wrong in what they think (or hope) others will pick up. If an actor's outsent intermediaries are not picked up, actors may still put in extra effort to make this happen - but they will not be able to 'sell' anything they want. In this way, the network 'indirectly' limits an actor's 'acting space'. Thus, actors are 'corrected' by the other actors in the network: the effect is that ongoing interactions can continue.

At the STN level, these three mechanisms add up to the emergence of resilience, and lead to a tendency for existing patterns of interaction (that is, STNs) to perpetuate. Thus, in contrast to occasional interaction, STNs reflect a longer-term coordination of activities by various actors. We will illustrate this in more detail in the empirical sections. Thus, the STN approach can help us cope with the systemic character of socio-technical development (requirement 4 above).

\section{STNs and their Environment}

Still, as empirical evidence shows abundantly, socio-technical change can take quite drastic forms: it may even lead to the complete disintegration of existing networks. In the STN approach, this can be accounted for by looking at the interaction between the STN and its 'environment'.

The characterization of STNs given above does not imply that interactions that are not included in the network are considered irrelevant. On the contrary, we need 'out-of-network' interactions 
to be able to cover inter-network dynamics and because, as we will demonstrate in the empirical sections, these are an important source of instability for the network. This may occur, for instance, because actors are typically part of more than one STN at the same time, and may therefore carry issues from one network to another. Furthermore, there is always the possibility of change triggered by incidental actions by actors not included in the STN. We consider such interactions not as interactions within the network but, rather, as interactions between the network and its environment. This (as we argued in the previous section) is because stabilized patterns of interaction play a role different from non-stabilized ones: the former show resilience whereas the latter do not. Defining STNs as an exemplification of stable patterns of interaction thus implies that interactions within the network are 'more durable' than interactions between the network and its environment. ${ }^{22}$ These interactions with the environment can, of course, develop into patternlike behaviours, thus making them part of network interactions. Eventually, completely new networks can develop in this way. This piece of dynamics is essential for the development of many new technologies which go hand in hand with the development of new configurations of actors - that is, new STNs.

Thus, on the one hand, we claim that existing STNs show a tendency to perpetuate (expressed as resilience) while, on the other hand, their interactions with the environment are essential for understanding important parts of technological change, especially radical technological change. Thus we fulfil requirement 3 formulated in the previous section.

With the above characterization of the STN approach (involving actors, intermediaries, technology, resilience and interaction with the environment) all five requirements formulated in the section on 'requirements for the framework' seem to be fulfilled. We will now elaborate the STN approach further on the basis of empirical material, notably the development of the European Fighter Aircraft.

\section{Case Study: The European Fighter Aircraft (EFA)}

In this section we will describe two episodes in the development of the European Fighter Aircraft (EFA). The description of each 
episode is followed by a discussion of issues in connection with STNs, raised in the previous section.

The first episode concerns the start-up phase of the project, in which its technological definition was subject to major controversy. On the basis of this episode, we will discuss how the STN approach can help identify the circumstances that lead to the development of a new network. Thus we will be able to highlight some characteristic features of a 'network-in-the-making'. At the same time, we will show how certain characteristics of the pre-existing networks set limits to the new network.

The second episode concerns the controversy that arose, some years later, over the EFA radar. In this phase, the network had matured and had become strong enough to (co-)determine its own further development. We will use this part of the analysis to show how the dynamics of the network as a whole can help us understand how one of the technological options was finally successful. This will help us shed some further light on the workings of resilience.

Very explicitly, we do not seek to give a detailed account of these developments that would satisfy the historian of technology: that would be beyond the scope of this paper. We will draw selectively on previously published work, and on a wide range of secondary literature. We will only sketch specific episodes in order to illustrate some of the features of STNs, and to elaborate some concepts further. Readers interested in a more detailed case description are referred to our earlier work. ${ }^{23}$

\section{Episode 1: The Birth of the European Fighter Aircraft}

\section{Prelude}

Plans for European cooperation in building a new fighter aircraft have been in the air since the late 1970s. A number of factors played a role in creating such initiatives:

- From the late 1970s onward, notions developed that US security interests differ in a number of respects from European security interests.

- There was a rising desire to become less dependent on the US in the field of arms production, ${ }^{24}$ while economic competition 
between the US and Western Europe led to the idea of becoming an independent competitive technological innovative power. Aerospace technology was considered to be a key technology in this respect.

- West European countries had to face very high R\&D costs, with a relatively small domestic market. ${ }^{25}$

The European Fighter Aircraft project had precursors in the British-led Experimental Aircraft Programme (EAP) and the French Avion de Combat Experimentale (ACX). The EAP followed from an initiative in 1979 by the British Aerospace company, together with the UK electronics companies Ferranti, GEC Avionics and Smiths Industries, to start developments on a new advanced technology aircraft. ${ }^{26}$ EAP was announced at the Farnborough International Airshow in 1982. The French reacted within weeks, announcing that they also had a national demonstrator programme - ACX, later called 'Rafale' - to be developed by the French aerospace company Dassault. Prototypes of both aircrafts were to fly at Farnborough in 1986.

The West German government, in favour of one common European enterprise for a new fighter aircraft, regretted this dual track. As it did not want to choose between these projects, it put pressure on the German aerospace firm, MBB, to withdraw from the British EAP. After this, serious negotiations started among five nations (West Germany, UK, France, Italy and Spain) on the joint development of a European Fighter Aircraft.

The importance of this brief 'prehistory' of EFA for our network analysis is to indicate that at the start of the negotiations over EFA some socio-technical networks, coupled to two different projects, were already in existence.

\section{Military Requirements for EFA}

Promoted by their national governments, the air force staffs of West Germany, France, Italy, Spain and the United Kingdom discussed the possibilities of a common new generation fighter aircraft. In December 1983, their discussions had matured to the point that the Chiefs of Staff reached agreement on a preliminary statement of the operational characteristics of what became known as the European Fighter Aircraft (EFA). The outline agreement, 
the 'Outline European Staff Target', emphasized air-to-air combat capability as EFA's primary requirement, with air-to-surface combat secondary. The outline target listed specific technological characteristics, including the type of armament. It was expected that the five partners would have a total requirement for about 800 aircraft while independent studies indicated that at least another 300 could be sold, primarily in the Middle East. ${ }^{27}$

In July 1984 , the defence ministers of the five nations met in Madrid and stressed the importance of the joint development of EFA. They signed an agreement for a formal EFA feasibility study, and made commitments to finance a study of the technology, and on work sharing for the airframe, engine and avionics systems. The countries compromised over an aircraft of about 9.5 metric tonnes, optimized for air superiority but with built-in ground attack capability. ${ }^{28} \mathrm{Up}$ to this point only those military requirements that were specified by the air force staffs had influenced the type of technology that was planned.

\section{Industrial Requirements - Heading for Trouble}

The next step in the EFA programme was to get the aerospace industries of the five collaborating nations to agree on work and design sharing, and on programme funding. Deeply rooted differences of opinion then became apparent.

First, there was the problem that French industries demanded design leadership of both airframe and engine: German and British industries wanted equal shares. ${ }^{29}$ The French position was rooted in its national security policy. After World War II, France developed a national armaments industry for all major categories of weapons, including advanced fighters. For a medium-sized country, however, sustaining a high-tech defence industry solely for domestic purposes creates a heavy burden on the national budget. This makes French industry and the political leadership very keen on export, to spread costs over larger volumes of production. ${ }^{30}$ In connection with the EFA development, the French concluded that a future fighter should be as light as possible to make it easier to export. This conclusion was based on a generally shared belief that fighters become more costly the heavier they get. $^{31}$

In STN terms, this means that, within France, long-standing 
weapon innovation networks have developed with strong ties between the government and a number of branches of industry that are considered strategic. In connection with the technology, some of the main issues in these networks were (1) keeping up innovative power, and (2) sharing development costs over larger volumes of production through export.

In the UK, the same issues played a role, but, when we take a closer look at the networks that had developed there, some important differences in emphasis appear. Much more than the French, British firms had developed relationships with foreign companies in the field of arms development and production. For instance, West Germany, Italy and the UK had cooperated before in the development and production of the Tornado fighter. ${ }^{32}$ Much more than the French, the British military and government relied on foreign technology (especially on American technology) for their armaments. So the British also wanted to become less dependent on the USA, but not by seeking national independence - rather, by seeking European cooperation.

Although the Chiefs of Air Staff had reached an agreement early on, differences of opinion on the military requirements for the fighter surfaced between the two countries. The Royal Air Force (RAF) believed - considering Britain's geographical relation to central Europe, ${ }^{33}$ and its long-range overseas responsibilities that a heavier, longer-range aircraft would be needed. The French, being closer to central Europe, did not need such longrange capacity. These different ideas about the tasks EFA should fulfil made the British want an aircraft that should be some $20 \%$ heavier than the French had in mind. ${ }^{34}$

In November 1984, the defence ministers convened and asked industry to present a design with two variants: one weighing 9.5 tonnes plus $250 \mathrm{~kg}$; the other weighing 9.5 tonnes minus $250 \mathrm{~kg}$. ${ }^{35}$ The French firm Dassault started working on the lighter version, and came up with a design which was derived from the Rafale demonstrator; Aeritalia, British Aerospace, Casa (Spain) and MBB (West Germany) worked on the upper limit, and produced a design that looked very much like the British EAP. ${ }^{36}$

Early in 1985, British Aerospace announced that it was prepared to give France design leadership in return for French agreement to an international development organization in which all members would be equal partners. This position reflected a certain desire for compromise but, on the other hand, it also 
reflected some strong differences with the French position. This was further emphasized when a seven-member British industrial consortium laid out a six-point programme for possible adoption as the UK position in negotiations with other EFA partners. This included a call for equality of management authority and responsibility among the five nations, with no overall leadership. ${ }^{37}$

In February 1985, industry offered two designs, neither of which completely fulfilled the European Staff Target, although the Dassault design was considered to be further from it than the proposal made by the other countries' industries. ${ }^{38}$ The proposals were discussed by the national armaments directors, but they failed to reach an agreement on design leadership, engine type and size. ${ }^{39}$ The defence ministers could not resolve the conflict either, and called for more studies on the air-frame and power plant configuration. The studies ordered included: ${ }^{40}$

- Studies of performance capabilities of an aircraft powered by an engine sized between 88 and $92 \mathrm{kN}$ (kilo Newtons) thrust and a second aircraft in the $80-85 \mathrm{kN}$ thrust range.

- Studies of possible interim engines.

This evaluation of the possibilities of different engine sizes was a further expression of the different meaning that EFA had for the French and British participants. French industry and government preferred the French Snecma M-88 engine that was already under development. Their preference for the M-88 was, at least in part, inspired by seeking a guarantee against the aircraft becoming too heavy, because this engine was designed for a 'low' $80 \mathrm{kN}$ thrust. On the other side, the Turbo Union consortium had built an engine for the Tornado fighter as a joint programme between West Germany, Italy and the UK: Turbo Union preferred an all-new engine. ${ }^{41}$ On the British side, the anticipated long-range mission implied a preference for a powerful engine. There was also a desire to upgrade the Tornado fighters somewhere in the mid1990 s with a new engine that would have a thrust over $90 \mathrm{kN} .{ }^{42}$

In early June 1985, industry presented 16 different, more refined designs. These plans were discussed by the ministers, but again they failed to make a choice. Once more they asked industry to make new proposals on a design of 9.5 tonnes plus $250 \mathrm{~kg}$ for potential additional mass. Three engines would have to be considered, with 84,88 and $91 \mathrm{kN}$ thrust, respectively. ${ }^{43}$ By mid-July, 
when these plans were presented, it appeared that there were still large differences of opinion. ${ }^{44}$

\section{Cutting the Knot}

By this time, West Germany found that negotiations were taking too long, and they started to push for a decision. The German defence minister, Wörner, declared that a decision should be made by 31 July 1985, at the latest. He made a number of compromise proposals to the armaments directors in connection with the technology to be used, type of organization and the staffing of various organizations. To the French, however, these proposals were unacceptable. ${ }^{45}$ On 1 August, during a marathon meeting of the armaments directors, the Germans cut the knot by choosing the British side. At that meeting West Germany, Italy and the UK signed a memorandum of understanding for the development of EFA. France and Spain could still join until midAugust. Under the agreement concluded, Germany and the UK would buy 250 aircraft each, Italy at least 100 . The total number of 600 aircraft was expected to cost $\$ 20$ billion. ${ }^{46}$ Shortly afterwards Spain decided to participate. ${ }^{47}$

France continued on its own, and pursued the development of the Rafale fighter. Like EFA, Rafale would be canard shaped, double delta-winged, but its mass would only be 9 tonnes, while EFA's would be 9.75 tonnes. The Rafale would be powered by two Snecma M88-2 engines, each developing $75 \mathrm{kN}$ dry thrust. ${ }^{48}$

\section{Evaluation: the Birth of a New Network}

The initiative for international cooperation on a new fighter came from the governments of (initially) five European countries. Although in a favourable position to promote such cooperation, our case makes clear that governments cannot simply 'instruct' their defence industries to do so. From their own perspectives, the various national industries saw no necessity for international cooperation. Industry preferred national to international solutions because of the uncertainties the latter would introduce over who would do what, who would get access to new technology, and so on. On the basis of their established relationships with govern- 
ments along national lines they knew what to expect, and they preferred to remain within those national frameworks. We will call them pre-existing networks, and from them the new network would be built. This reluctance of national industries beautifully illustrates the resilience of established networks against altering existing patterns.

Still, the new EFA network did emerge, thanks to the continuous effort various governments put into making it happen. This leads us to conclude that, in order to build a new network out of preexisting networks, one or more actors are needed who, for one reason or another, do not take the existing patterns of interaction for granted. For two reasons, these actors have to work against the odds. First, they act counter to existing patterns of interaction (that is, STNs) of which they themselves are a part, and they have to counter pressure from actors trying to prevent them from doing so. Secondly, they have to enrol new actors who are also part of existing networks: they therefore have to make additional effort to overcome the resilience of these other, extra networks. Actors who are prepared to put in all this effort, we will call dedicated network builders.

This, of course, raises the question of what makes actors turn into a (partial) dissident in a pre-existing network, seeking to create a new network. The obvious answer is that they faced major problems in the existing networks. In the case of advanced fighters, the European governments faced three related problems - namely, (1) the increasing costs of new generations of fighters; (2) increasing budgetary constraints; and (3) the declining harmony of interests with the US as a security guarantor.

The increasing budgetary constraints are interesting from the STN perspective, since they demonstrate that governments are actors, not only in the weapon-innovation network, but also in a variety of other networks. This illustrates the importance of internetwork interactions (that is, interactions with the environment), and shows that actors can carry issues (such as shrinking budgets) from one network to another.

Looking at the fighter network, we see that, for some actors, almost all their interactions are within the framework of that network - for example, for a company like Dassault. For others (for example, governments) this may only be true for a small part of their interactions, because they operate in many other networks as well. Following the SCOT approach, we will use the word 
inclusion $^{49}$ to denote the degree to which an actor's interactions are framed within the network under analysis.

Summarizing the arguments above, we conclude that actors with a relatively low inclusion in pre-existing networks are most likely to get themselves into a position that they can then turn to their advantage, transforming themselves into dedicated network builders seeking to construct a new STN. We will return to this point later.

In the EFA case, the dedicated network builders had to enrol other actors, such as the air forces and national defence industries. The conflicts of opinion that surfaced were not simply reflections of differences of opinion between single actors: rather, it appeared that two different pre-existing networks had to be accommodated, notably two experimental programmes that were already running - the British EAP and the French ACX.

At face value, one might have expected that the establishment of the 1983 'Outline European Staff Target' by the air force staffs would have created sufficient coherence to develop a technology to fulfil those requirements. However, by focusing on the preexisting networks rather than on individual actors, we can see that this was unlikely to happen because those requirements were at odds with some characteristics of the pre-existing networks. The resilience of those networks implies that the new network will either have to adapt, or it will not be able to enrol actors from preexisting networks.

Here, when compared with the SCOT approach, the STN approach has additional value. The SCOT approach could, to some extent, elucidate the positions of the actors involved, but it cannot explain the large differences between the French and the British. The British and French governments negotiated not only as representatives of a relevant social group but also as actors in pre-existing national networks. Existing patterns of interaction (that is, STNs) co-determined their position.

\section{Episode 2: The Battle over the EFA's Radar}

\section{The Continuing Story of EFA}

Before discussing in detail disputes over EFA's radar, let us first sketch out some further general background. The development phase of the EFA programme was supervised by an International 
Project Office called the NATO European Fighter Management Agency (NEFMA) which, de facto, represented the four Defence Ministries of the participating countries. The management agency would have a final say on certain items such as the radar and engine. ${ }^{50}$ Industries of the four nations formed a consortium called Eurofighter, based in Munich, to carry out the actual development work. Another four-nation consortium, called Eurojet, would manage production of the EFA engines. ${ }^{51}$

In May 1986, the air force staffs of the remaining four nations accepted basic design parameters that called for an aircraft with a 9.75 tonne mass, two engines of $92 \mathrm{kN}$ thrust each and a wing area of 50 square meters. This design met the operational requirements of all four air forces. In the autumn of 1987, work conducted had led to a further freeze of EFA's design; the air force Chiefs of Staff formally signed the EFA European Staff Requirement for Development in September 1987. ${ }^{52}$

We will now discuss in detail what subsequently happened in connection with the development of the EFA radar.

\section{The Radar - EFA's Eyes and Brains}

Radar fulfils a critical role in most fighter missions. Except for close air combat, where performance (for example, agility) of the fighter is a crucial factor, its usefulness largely depends upon the radar and the weapons carried. Requirements for the radar depend upon the missions of the aircraft, as envisaged in the military need which is formulated by the air forces. A radar should enable search, detection, identification and tracking of enemy aircraft. Subsequently, it has to guide missiles to these targets or to provide initial data for launching weapons that have their own homing devices. Increasing demands are put on the detection range capability. In addition, the radar system has to warn the pilot of approaching enemy missiles, and to provide electronic counter-measures.

Two Radar Consortia: ECR-90 contra MSD-2000

When France was still part of the EFA consortium, the French electronic giant Thomson-CSF talked with Ferranti (UK) and 
AEG-Telefunken (Germany) about collaborating on radar and avionics systems for the fighter. In early 1985, in spite of the threatening split-up of the five-country EFA cooperation, Thomson still looked for possible cooperation with these companies and with the Italian FIAR and Spanish EESA companies. ${ }^{53}$ After the break with France, however, Thomson-CSF dropped out.

This episode clearly illustrates the additional value of the STN approach over the SCOT approach. In the latter, Thomson-CSF would belong to the relevant social group of 'electronics firms', just like Ferranti, AEG, and their ilk. As they would thus all be 'equal' in the analytic sense, this could not explain why ThomsonCSF dropped out. In the STN approach, however, actors building up a new network are also actors in pre-existing networks. This makes us aware that, to get EFA 'off the ground', pre-existing national arms-production networks (including national government and industry) had to be accommodated. That makes it easy to see why Thomson had to drop out when the French government decided to stop its participation in EFA.

Subsequently, two consortia emerged in the competition over the radar, which had an estimated market value of about $\$ 1.5$ billion. ${ }^{54}$ The British company Ferranti, leader of a consortium including the Italian FIAR and Spanish INISEL, offered a radar, called ECR-90 (European Collaborative Radar for the 1990s), based on the development of Ferranti's Blue Vixen multimode radar. Since 1983, the Blue Vixen was developed as part of the Mid-Life Update Programme of the British strike/attack aircraft Sea Harrier. The ECR-90 would thus resemble radar technology used elsewhere in the British armed forces. The operation of the ECR-90 would be largely controlled by software which could be tailored to the needs of different users. Work within the ECR-90 consortium would be divided according to the number of aircraft ordered by the EFA member nations. Important to the participating countries was that each of the consortium members would assemble and test complete radar systems, and would have access to all the technology developed. ${ }^{55}$

The second radar candidate, called MSD-2000 or 'Emerald', was a derivative of a radar developed by the American company Hughes for the US Navy F/A-18 Hornet fighter. This radar had a proven performance for a complete set of air-to-air and air-tosurface modes, and had a growth potential to meet EFA radar 
requirements. ${ }^{56} \mathrm{~A}$ derivative of this radar was offered by the US/ German consortium of Hughes and AEG. This radar would also be used in the update programme of the F-4 fighter; this would allow Germany to use spares bought for its F-4s, and also to use the radars themselves when the F-4s would eventually retire. ${ }^{57}$

In the contest over EFA's radar, the two consortia (as well as the individual companies) tried to strengthen their position by linking up with other companies. Thus they tried either to increase their technological capacity for developing more capable radar systems by adding new know-how, or to strengthen their position within particular EFA countries. They emphasized those issues that appeared to be important for the decision-makers, like exportability, technological capability, flexibility, reliability, growth potential, and so on.

The UK, together with Italy, had the most demanding requirement for the radar. In the competition between domestic electronics firms for participation in the EFA radar, the UK had chosen Ferranti (leaving out its main competitor, the British electronics company GEC) and subsequently kept pushing Ferranti in the international competition. ${ }^{58}$ On the other side, the German government strongly supported the MSD-2000 (Emerald) radar. Its main objection to the Ferranti radar was its risk in technological development, and consequently in costs. Germany was also seeking commonality with its F-4Fs, that were to be upgraded with a Hughes radar and equipped with the same weapons as scheduled for EFA ${ }^{59}$ Consequently, to German pilots, the EFA radar would appear virtually identical to the radars in their F-4Fs. (The same consideration applied to the upgrading of the Blue Vixen in the British position.)

What is interesting here, in STN terms, is that we are not simply dealing with 'developing technology' on demand, but with two different sets of actors connected to two different technologies that is, two STNs. We have the STN of the ECR-90 and the STN of the MSD-2000, and one of these eventually had to become part of the EFA-STN. What makes the analysis somewhat complicated is that some of the actors involved are part of more than one STN. This seems the right place, therefore, to present a schematic representation of the various relevant STNs (see Figure 1 on pp. 118-19).

Figure 1 illustrates that we are dealing with two different radar networks, the boundaries of which largely run along national lines. 


\section{FIGURE 1}

\section{EFA-STN, MSD-2000-STN and ECR-90-STN}

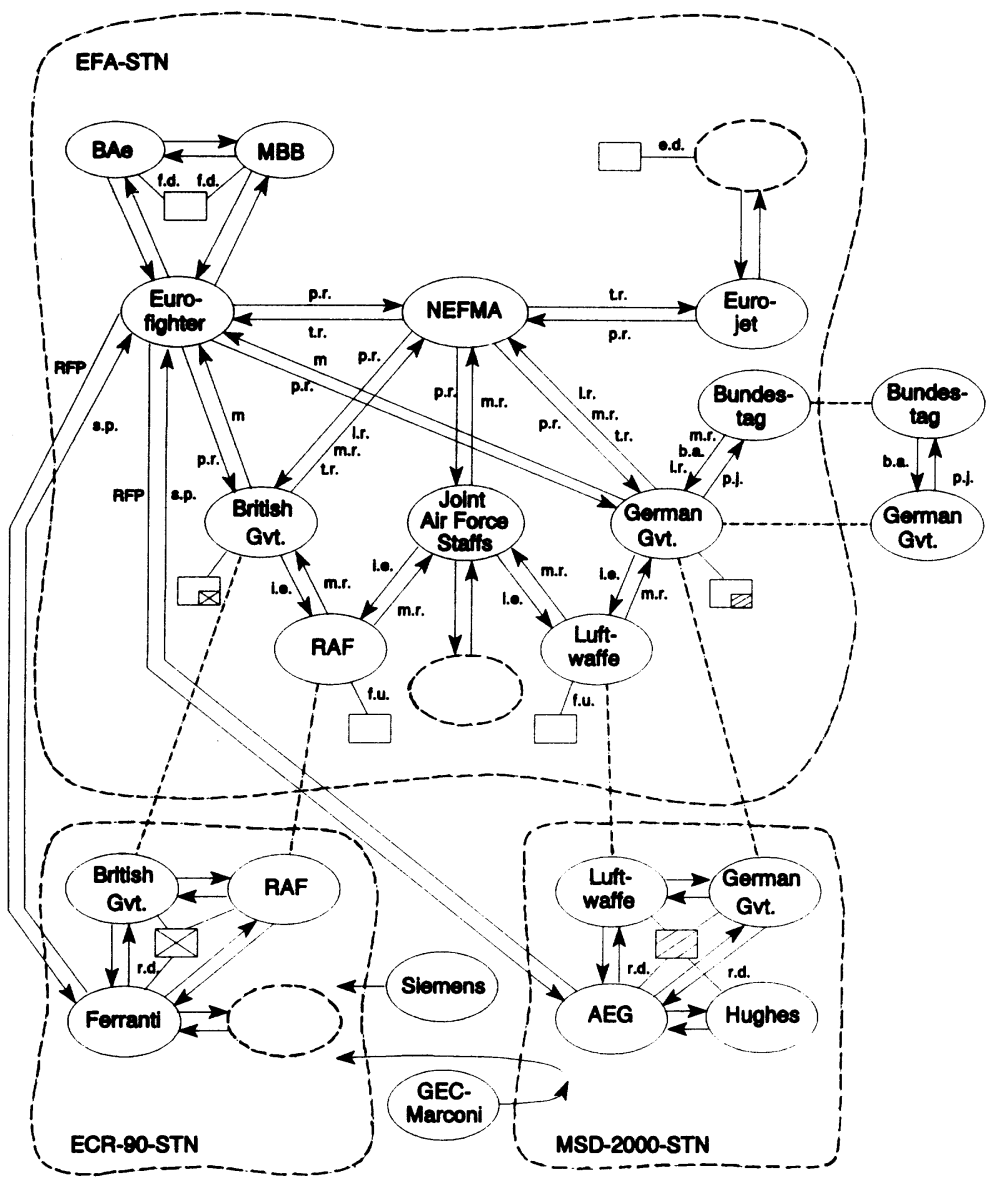


Explanation of the various symbols used

\section{STN and Environment}

- The dashed closed line indicates the boundary of the various STNs. Beyond the rectangle is the network's environments.

Actors

- The ovals denote the actors. Actors can be part of different STNs; a dotted line between two STNs indicates that the ovals connected denote one and the same actor, belonging to different STNs. These dotted lines indicate that actors can carry issues from one network to another.

- Acronyms used for actors

AEG = AEG (German electronics company)

$\mathrm{BAe}=$ British Aerospace

MBB = MBB (German aerospace company)

NEFMA = NATO European Fighter Management Agency

RAF $=($ British $)$ Royal Air Force

- To make the picture not too complicated, only the German and British actors are represented. A dotted oval indicates that several other actors are also part of the network.

- Some actors (outside the STNs) are indicated, and will be discussed later in the text

Intermediaries

- The lines with arrows indicate the intermediaries that go from one actor to another. Typically, there are two lines between two actors indicating that intermediaries go both ways. The intermediaries are labelled according to what is going in the direction of the arrow.

- Acronyms used for intermediaries

b.a. = budget appropriations

i.e. $=$ information exchange

i.r. $=$ industrial requirements

$\mathrm{m}=$ money

m.r. $=$ military requirements

p.r. = progress reports

p.j. = policy justifications

RFP $=$ Request for proposals

s.p. $=$ submitted proposals

t.r. $=$ technical requirements

- To keep the picture simple, not all the intermediaries are labelled.

The Technology

- The rectangled boxes connected to the actors denote the actor's version of the artefact. These denote what characteristics of the artefact are of specific relevance to that actor. As this may vary across actors, all these artefacts are different.

- In case a subset of actors would find the same characteristics of relevance, this can be indicated by 'hanging the artefact between these actors', as is done in the case of MBB and $\mathrm{BAe}$ and in the cases of the two radar-STNs

- The artefacts hanging below the British and German governments in the EFA-STN are drawn with different subsections to indicate that they favoured different radars.

- Acronyms used to characterize relationship between actor and artefact:

e.d. $=$ engine development

f.d. = fighter development

f.u. $=$ fighter use

r.d. = radar development

- In a complete STN, each of the actors involved should be connected to (its version of) the artefact. Here we have only indicated a few that highlight some of the issues discussed in the text. 
This is comparable to the situation when France was still a candidate to participate in the EFA-network-in-the-making. Then, the issue was resolved by cutting the knot, whereupon all the French actors dropped out (and after which Thomson-CSF failed in its attempts to hook on on its own). In the case of the radar, however, cutting the knot appeared to be not so easy. As we will illustrate below, it was difficult to take actions that went against what other actors in the network found relevant: the EFASTN started to demonstrate its resilience.

\section{Fierce Competition}

Initially, disagreement over the radar was formulated mainly in terms of differences in the (required) capabilities. The EFA partners even considered a split buy: West Germany and Spain, the MSD-2000; ${ }^{60}$ Italy and the UK, the ECR-90.

In July 1986, the Hughes/AEG consortium strengthened its position by linking up with the UK company GEC Avionics (later GEC-Marconi). The addition of the GEC signal processor would allow two versions of the Hughes radar to be offered - one with only relatively minor modifications for Germany and Spain, and a more sophisticated one equipped with the GEC processor for the UK and Italy. ${ }^{61}$ Like the competing ECR-90 consortium, GEC now emphasized the importance of flexibility and growth potential in the Hughes radar, arguing that the military threat might have substantially changed by the time that the radar would go into service (that is, the mid-1990s).

The 'official' battle for the radar started in December 1986, with the Requests for Proposals (RFP) issued by Eurofighter to 15 radar manufacturers in the four countries and the USA. ${ }^{62}$ The winner was to be selected by Eurofighter (that is, the industrial consortium) in the spring of 1987 . The choice would be made primarily on technical and economic criteria. It appeared, however, that the decision was heavily politically laden. Eurofighter started changing the specifications and extended the bidding several times. The growing discord made Hughes/AEG submit two proposals, offering one radar that would be fully compliant with the latest specifications, and another, shorter-term version that would not be fully compliant but would cost significantly less. ${ }^{63}$ 
In late 1987, Eurofighter, to get out of the deadlock, asked for refined bids for a less expensive radar. To this end some of the initial requirements (mainly of a technical and commercial nature, and less to do with performance) were relaxed. Like the AEG/ Hughes consortium, Ferranti now offered a less expensive radar, notably a variant of the Blue Vixen radar. ${ }^{64}$ This procedure brought no solution, however, and in the summer of 1988 Eurofighter handed the EFA management agency (NEFMA, the political organization) a split recommendation to decide upon. ${ }^{65}$

In late 1988, negotiations on the radar became tougher. The issues that dominated the negotiations and interactions were (1) risks in development and production costs, and (2) export restrictions by the USA. The technological capabilities of the radars were no longer an issue. Thus, at this stage, the military and the technologist actors had shifted to the background.

At NEFMA meetings (basically representing the Ministers of Defence) in December 1988 and early 1989, West Germany took an uncompromising position and warned that it would proceed with the MSD-2000, thus threatening a split choice. ${ }^{66} \mathrm{~A}$ breach over the radar, however, threatened the EFA consortium as a whole, since selection of one common radar had been part of the basic Memorandum of Understanding. ${ }^{67}$ In this clash the United Kingdom, supported by Italy, stood firm on the ECR-90. ${ }^{68}$

It is illuminating to evaluate this episode in STN terms. At first sight, it seems odd that the military requirements and technological capabilities of the radars could lose their significance as evaluation criteria. However, as Figure 1 illustrates, we are not simply dealing with requirements and technologies to satisfy them; we are dealing with socio-technical networks that demonstrate resilience. On the one hand, we have two radar-STNs in which national jobs, national prestige and the national technology base played an important role; on the other hand, we have the EFA network to which some of the national actors are also committed, and which they do not want to put at risk. Looking at Figure 1, it then seems that the situation is in a complete deadlock.

Whereas Eurofighter had left the decision to NEFMA because it was too political, this agency apparently hoped that a decision could still be made by Eurofighter on technical grounds. Therefore, in February 1989, NEFMA instructed the Eurofighter consortium - for the third time - to re-evaluate the two bids, and make a recommendation on the radar. Again, this did not work: 
the (political) conflict had thus to be resolved at senior government levels.

In West Germany, the Ministry of Defence was under heavy pressure from the Bundestag to limit the costs of EFA and its radar. ${ }^{69}$ To prevent a complete failure of the common radar project, the UK Ministry of Defence tried to meet the German objections by offering to underwrite the risk on the ECR-90. ${ }^{70}$ To defuse a crisis, it was agreed at high-level consultations between the UK and German Secretaries of State for Defence that the EFA radar would adhere to current budget and time schedules, and would not result in an 'uncommon' radar solution (as had been threatened by West Germany).

The negotiations on the financial and technological risk issue, so strongly pushed by the Germans, were marked by several moves on both sides. To secure a choice favourable to Ferranti, the UK Chief of Defence Procurement suggested (in a confidential memo) that Bonn direct MBB (the German aerospace firm) to transfer DM 150-300 million of EFA work of its choice to British Aerospace. This would allow the Germans to retain cash reserves to offset Bonn's perception of the risk associated with the ECR-90. West Germany reacted sceptically to the British proposal, saying that a transfer of work would not only take jobs away from MBB, but would also remove valuable technological know-how that Germany hoped to gain from the EFA programme.

In the meantime, the company-actors tried to consolidate their positions. Ferranti strengthened its hand by concluding an agreement with Siemens, giving ECR-90 an 'active' West German partner. ${ }^{71}$ In addition, both Ferranti and the German electronics firm AEG were working on reducing the cost of their radar bids to present 'best and final offers' by early April 1989, in accordance with Eurofighter's latest instructions. ${ }^{72}$ In the summer of 1989, NEFMA and government officials met again, ${ }^{73}$ after which Eurofighter asked the two bidding teams to submit yet another round of best and final offers. ${ }^{74}$

At that time, West Germany mounted a 'counter-offensive' to British risk guarantees, offering to pay almost all of the cost of optimizing the AEG-led MSD-2000 radar to satisfy the British requirements for EFA, and guaranteeing to underwrite development risk. This initiative was virtually a mirror-image of the earlier British proposal to underwrite the risk of the Ferranti-led ECR-90.

During 1989, Ferranti ran into financial difficulties, due to a bad 
takeover in 1987 of its International Signal \& Control Group. A number of companies considered buying Ferranti because of its high-tech base and, early in 1990, this led to GEC buying Ferranti's radar division. ${ }^{75}$ Although not triggered by it, the EFA radar controversy did play a role in this strategic takeover, as the British government had encouraged GEC to buy Ferranti in order to reassure the EFA partners that the ECR-90 radar would continue. ${ }^{76}$

The result of all these moves was that the ECR-90 had strengthened its position substantially. First, teaming up with Siemens in 1989 now meant that the ECR-90 had acquired an active proponent in Germany. Secondly, the GEC takeover of Ferranti, combined with GEC's strong financial position, implied that the financial risk in developing the ECR-90 would be lower. ${ }^{77}$ In addition, GEC now became a strong advocate of the ECR-90. Finally, in May 1990, the final decision was made: the ECR-90 was selected to become EFA's radar. ${ }^{78}$

Looking at Figure 1, the episode described above means that at a certain point GEC became a member of the MSD-2000 network, whereas Siemens became an actor in the ECR-90 network. With GEC's takeover of Ferranti, however, the former decided to drop out of the MSD-2000 network, and become an actor in the ECR90 network. This satisfied the German government that possible financial risks remained acceptable, while the participation of Siemens secured that Germany would also benefit from radar development. Thus the German government also became an actor in the ECR-90 network, and this tipped the balance.

\section{Compromise Found: Increased Resilience Against New Threats}

Reaching a unified decision on the radar was important for the EFA project as a whole: a 'time bomb' was removed. In Figure 1, the difference between the 'EFAs' connected to the German and the British governments, respectively, had disappeared. As a result, the EFA network was reinforced by its commitment to a specific radar. New actors had been connected which increased the network's resilience.

New threats emerged, however. With changes in Eastern Europe in the late 1980s, and the subsequent defence budget cuts in 
Western Europe, EFA's future became insecure once more. In Germany, especially after German re-unification, various members of parliament questioned the need for an EFA. Both the German Social Democrats and the Liberal Party called to end its development. ${ }^{79}$ This posed a serious threat to the EFA project, and other actors within the EFA network reacted. For instance, in March 1990, the UK Air Vice-Marshal John S. Allison reiterated Britain's support for the EFA programme 'despite the lessening of tensions around the world'. Rather than reducing the need for EFA he argued that such '[m]ultipurpose weapons as EFA will become increasingly important'. Also Johann Schaffler, president and chief executive officer of Germany's MBB (which had a 33\% workshare in EFA development), suggested that reduced threat does not necessarily mean more stability, and that NATO and the Warsaw Treaty Organization might gain new importance in guaranteeing stability. ${ }^{80}$

Nevertheless, in the West German Bundestag opposition against EFA grew, especially in view of the high costs of German re-unification. This even led the German Minister of Defence, Volker Rühe, to declare EFA 'dead' a number of times in early 1992. The EFA network demonstrated its resilience, however, when various actors put in considerable effort to find compromises to meet this German opposition. Late in 1992, this led to a new compromise where EFA was redefined as the 'New European Fighter Aircraft' (NEFA: called 'Jäger Light' in German-English) that would cost DM 90 million a piece, rather than DM 130 million (excluding VAT). ${ }^{81}$ Ironically, the requirements for NEFA very much resemble the French requirements for EFA that were not acceptable to the Germans and the British in 1985 (making the French step out of line and develop their own fighter, Rafale).

\section{Evaluation: Surviving Adolescence}

While the EFA network was formed through the establishment of the NATO European Fighter Management Agency (NEFMA) and the industrial consortia Eurofighter and Eurojet, it built up a resilience of its own, and a resistance to falling apart.

As was the case in EFA's birth, military requirements initiated interactions over the radar design. One might have expected that the technology chosen would be the one that best fitted these 
requirements. However, it appeared that the main stumbling blocks were not the translation of the requirements into technology, but rather costs and appeals to what might be called the 'national technology base'. The resilience of the pre-existing national industry-government networks showed once again when both Germany and the UK preferred a radar that was in accordance with the national update programmes already running in their defence industries. Instead of cutting the knot (as happened when France dropped out), for more than three years the dedicated network builders tried to find a compromise that would not cause a split. This shows that the resilience of the EFA network had grown as more actors had become committed to it. Keeping the interactions going became a major goal for these actors.

It is striking how, in the later discussions over the radar, the arguments were hardly in terms of linking technologies to requirements but, rather, which technology (or better: which combination of companies) might enable the EFA network to perpetuate itself. The differences in technical performance of the two radars shifted to the background. Aware of this change, the competing companies teamed up strategically with companies from the 'hostile' countries. The team that finally won was the one that was quickest in making the proper strategic moves - that is to say, the consortium that most quickly removed doubts that national industry would remain on the backbench, and that cost would be overrun.

Since we are developing the STN approach as a stepping stone towards solving problematic aspects of socio-technical development, it is important to understand how, in the interactions between the actors, the technology acquires its specific shape. For EFA, the radar requirements were derived from its anticipated missions. This, however, still left plenty of room for negotiations on the concrete shape of the technology. We have already concluded that the resilience of the network to a large extent determined what technology was finally successful. Resilience limited the range of solutions that could facilitate the network interactions to continue.

Looking at the interactions in more detail, the actors in the end decide what solution to accept or not to accept. They will judge which characteristics of the artefact are essential to them and which are unacceptable - and how, in interaction with other actors, they can best realize what they consider important. In these private evaluations, the results of past interactions are a starting 
point. These results may refer to 'accepted' technologies, 'accepted' criteria for evaluation, 'accepted' participating actors and other characteristics. 'Accepted' in this case means de facto acceptance by all relevant actors - in other words, that these factors are no longer questioned. Negotiations will then start over those factors about which there is no de facto consensus, to find a compromise.

As these accepted factors are the starting point of further interaction and technological development, they can be seen as the factors that build up resilience. Let us take a closer look at what these factors are in the radar case. In their judgements, all actors more or less shared the following considerations:

- performance capabilities were important as long as costs would not become too high;

- commonality of the radar choice was considered important, to limit the costs of systems integration;

- companies from all four countries should participate, so that every country would benefit in gaining know-how;

- the chosen solution should contribute to the continuity of the four-country EFA network.

This is a very heterogeneous set of considerations. Obviously, resilience cannot be seen as a simple quantitative measure: STNs show resilience, but its concrete workings do not seem to follow a simple logic. To investigate this further, we must compare a variety of case studies; this might enable us to identify some typical patterns.

Still, we can make one general remark about resilience: it can be observed at the network level. Interactions in the network take a form that can continue. Resilience thus connects the past and the future. Interactions that threaten continuation tend to be 'filtered out'. However, we also have to look at the actor-level: not all the interactions that might keep the network going are acceptable to different actors. We therefore also have to look more precisely at what characterizes each actor if we want to understand which technologies (and other intermediaries) 'fit'.

Summarizing, at this stage in the development of the STN approach, we have to identify the constituting factors of resilience in every specific case before we can determine which technologies are more or less likely to 'make it'. In further work, by comparing 
various cases, it may be possible to distinguish various typical types of resilience.

On the basis of the EFA case, there is one further issue we want to discuss: the interaction between the STN and its environment. Although various compromises were reached, leading to increased resilience of the EFA network, its further. existence remained continuously under threat. As described, the latest threat was the rising opposition to EFA in Germany. This opposition was triggered by what we would call 'external' events. This warns us that actors in a network should never be considered as isolated from their 'environment': network dynamics should not be analyzed exclusively in terms of the network itself.

In Figure 1, the German Bundestag is represented as an actor that is both part of the STN and of its environment. It is part of the STN because its interactions in relation to EFA have a recurring and patternlike nature. In its (infrequent) debates on the fighter, the Bundestag judged it from the perspective of various national issues, including budgetary, military and industrial considerations. By far the most of the Bundestag's activities, however, deal with issues other than EFA, making the Bundestag part of the EFASTN's environment. In that environment it has developed a stable pattern of interaction with the German government in which budget appropriations are a major item. It may also influence the interactions in the EFA network by this route, as is indicated in the figure.

In STN terms, the Bundestag's positioning means that this actor has a low inclusion in the EFA network. In general, parliaments are concerned with a broad scope of political, economic and budgetary issues and are also, through their members, actors in a host of other networks. Their inclusion in specific weapon innovation networks is typically lower than for governments, while members of parliaments have an even wider diversity of interactions with other networks than governments have. ${ }^{82}$ Because their commitment to the development of a specific weapon system can be very low, and because their judgement is influenced by a wide variety of considerations, parliaments can become a 'destabilizing' actor in an STN.

While parliaments have a low inclusion in the STN under analysis, at the same time their support is (considered) essential for the network to survive, because parliaments can cut or withhold the necessary budgets. This gives them a special status in 
the network, for which we will use the phrase critical actor. The support of critical actors is considered essential, but it cannot be guaranteed. The lower their inclusion in the network, the less they are committed to what has been built up, and the less they will be inclined to adapt. ${ }^{83}$ By contrast, the other actors in the network, depending on just how vital the critical actor is considered to be, will be prepared to adapt to a critical actor's whims in order to keep the interactions in the network going.

\section{Discussion: STNs and the Guidance of Technological Development on the Basis of Societal Priorities}

\section{Dynamics of Socio-Technical Change in STN-terms}

It is evident from our cases that, in the analysis of technological development, it is important not to focus merely on the technology involved, but also to take notice of the shaping of the social dimensions of the surrounding network. The cases show that a specific, historically grown pattern of social relations around specific technologies time and again appeared to be a very important factor in directing the subsequent course of technological innovation.

Based on our analysis above, we see the following dynamics in the development of an STN. Initially, dedicated network builders play a prominent role. In a network-in-the-making, the dynamics of the pre-existing networks in which the builders function, and the problems they face there, to a large extent determine what type of technology they try to construct. Especially when networks are relatively small and the dedicated network builders are fighting for survival, adaptations in the technology are easily made. The builders then have to enrol new groups of actors (especially critical actors), and they attempt to do this by adapting the artefact, to some extent, to the wishes of the actors to be enrolled. Enrolling new actors then introduces new themes, originating from the preexisting networks in which these actors participate. These new themes co-determine the further course of technological development.

In this process, the STN builds up resilience. In some cases, specific characteristics of the technology can be 'the glue' that links 
various actors together. This makes these characteristics into a constituting element of resilience: they have become a starting point for further development, and are not (easily) questioned again. The EFA case shows that once new (groups of) actors had been committed to the network, the technological features of the artefact that accompanied their enrolment (like deciding for a specific radar) became more fixed, and changing them became less easy.

This general picture of the dynamics of STNs should be refined so that we can be more specific about what happens to the technology. We must do this because we are seeking to use the insights gained to deal with societal problems related to specific technologies. From our analysis, the following lessons can be inferred:

(a) When attempting to understand how actors behave in developing and using technology, it is not sufficient to look at them as a single entity with specific characteristics. Existing patterns of interaction with other actors and with technology (that is, existing STNs) co-determine their behaviour.

(b) Existing STNs show resilience. This implies that within an STN those changes are most likely that enable the interactions to continue. This implies that changes that are problematic for one or more actors are less likely to survive.

(c) The more 'complex' an STN is (by which we mean that it includes different types of actors, whose interest in the technology stems from different backgrounds), the more likely it is that a change in technology will be problematic for one of them. In combination with lesson (b), this implies that in such 'complex' STNs technological change is likely to take place with relatively small modifications at the time.

(d) In principle, technological change takes place along two routes:

(1) Within existing STNs. This can be part of the internal dynamics of the network (for example, to keep ahead of competitors), or it may result from the introduction of new themes from outside by actors with a relatively low inclusion. As concluded above, these innovations can be expected to be conservative. (Over longer periods of time, of course, many small changes can add up to major differences.) 
(2) Through the emergence of new STNs. Here, of course, radically new technologies may be developed through cooperation between new types of actors.

\section{Subjects for Further Research}

The lessons inferred above are still too general for us to make an assessment of the likely and possible future trends in ongoing technological developments. To facilitate this, we think that the STN approach should be developed further. In particular, we think that the following two sets of questions are of relevance:

(1) Is it possible to distinguish various typical forms of STN development? These typical forms may be related to the types of actors that are participating (dedicated network builders, critical actors, possible other typical actors), the types of intermediaries that flow between them, characteristics of the relationships between the various actors and the artefact under study, the types of links the actors have with the environment, and so on.

(2) Especially in connection with our final aim of investigating possibilities to 'guide technological development on the basis of societal priorities', it is important to gain a better understanding of the building-up and the working of resilience. To a large extent, resilience determines which alternative courses are possible. It may be possible to distinguish various typical forms of resilience, and these might be connected to the network characteristics listed in point (1).

If we can answer these questions on the basis of a variety of further case studies we think that we can greatly facilitate attempts to make more detailed assessments of possible and likely future developments of existing STNs.

\section{Specificity of the Case Study}

A problem of our analysis is, of course, that we base our conclusions on a single case study - and, moreover, that we look at a very specific domain of technology, namely military tech- 
nology. Weapons development is often seen as having a specific dynamics, different from that of many other technologies. For instance, students of international relations will find little surprising about states pursuing their national technical programmes, consistent with their military strategies and in support of their national defence industries. For them it may be no surprise that the French stepped out of EFA.

This may be true, but in the battle over the EFA radar, the same kind of national divisions did not lead to a 'forced decision'. It is here that the STN approach has additional value, since it points to the resilience built up in the international EFA network which prevented unilateral decisions along national lines. At least, we can say that the STN-approach lends additional explanatory power in a case where national development processes were overruled by international ones.

Of course, we cannot conclude on the basis of the single case study presented here that the model has general applicability. Still, our past and current work in other technological domains convinces us that the model has wider applicability than just the military case. In car development and use, for instance, a very resilient network has developed with the major car manufacturers as important actors. In the late 1980s, the state of California implemented some strict air-pollution regulations that virtually mandated the introduction of electric vehicles in California by 1998. The major car manufacturers were very much against this regulation because it would be impossible to make and sell such vehicles for acceptable prices. Since then, however, new networks have been emerging around new industries that are developing and selling electric vehicles. This has forced the main automotive companies to change their policies: in some cases, they have even started joint ventures with these upcoming industries. In this case, too, an analysis in STN terms is illuminating: it illustrates how very radical innovations can take place outside (rather than within) a resilient existing STN, which can subsequently affect the dynamics of that STN. It underscores both the conclusions (d)(1) and (d)(2), drawn above. ${ }^{84}$

Although a single case study cannot prove that the STN model has wider applicability, we have good reasons to believe that it does. More important, though, is that we have been able to formulate questions as to how the model should be elaborated in future work. The model should then really demonstrate its value. 


\section{Towards Guidance of Technological Development on the Basis of Societal Priorities}

In this paper, we basically set out to develop the STN approach as a model of analysis for socio-technical change. As we stated at the start, however, in developing the model we are inspired by our final goal of developing possibilities for 'guidance of technological development on the basis of societal priorities'. Although this second step demands further work, the analysis above already allows us to draw some preliminary conclusions, and to discuss the potential value of the STN approach from the perspective of our final goal.

We think that two major conclusions can be drawn on the possibilities for guidance of technological development in order to solve the problematic aspects for society. These are:

1. Inducing change within existing networks is only likely to work if relatively minor changes are considered necessary to solve the problem, or if a critical actor would stand firm on requiring change. In principle, governments, government agencies or parliaments could take that position, but they typically do not tend to take measures that are strongly opposed by important other actors in the network (which illustrates the network's resilience). They will only seek to counter the resilience of the existing network (and thus turn into a dedicated network builder for a new network) if they feel that the magnitude of the problem faced leaves them no choice. An example would be the stringent low-emission and zero-emission vehicle regulations in California, which were enforced because of very poor air quality, particularly in the Los Angeles area. ${ }^{85}$ Such an approach, however,cannot be expected for a problem that is less visible, and over which there is less consensus that it is a problem (like the issue of global warming due to the combustion of fossil fuels).

2. Starting a new STN could bring about more radical changes in shorter time, but this route is much more complicated. Such an approach would only solve the problem at hand if the old technology could be phased out - that is, when emergence of the new network would lead to the disintegration of the old network that is related to the old technology. Let us briefly indicate some necessary elements 
to make such an approach work. First, a new technology would have to be identified that holds a certain promise, and that does not have the problems of the existing technology. Secondly, one or more dedicated network builders would have to be found who would be prepared to work against the odds. (These could be, for instance, start-up companies that expect large profits if the new technology found large application. It could also involve a subset of users with relatively low inclusion in the existing network, and/or who are particularly sensitive to the problems of the old technology.) Thus, a small network-in-the-making could emerge in which the new technology could be further developed, to make it attractive to ever-more users in the old network. When successful, the new network would gradually 'suck' ever-more actors out of the existing network, and gradually 'bleed it to death' ${ }^{86} \mathrm{~A}$ possible alternative would be that the existing network could incorporate the technology (and actors) of the new network, because it comes to be seen as a major threat.

These suggestions, of course, are still far from a complete approach to the problem of guiding technological change on the basis of societal priorities. They do make clear, however, that the STN approach can lead to specific ideas about how to tackle such problems. This, in its turn, leads to suggestions about how the STN approach should be elaborated further. For instance, given the crucial role of dedicated network builders, it is important to investigate what strategies they can best use, and under what circumstances. Whom should they enrol first, and how can they optimize their chances to make their network grow, partly at the expense of an existing STN that can be expected to demonstrate its resilience?

In seeking to relate strategies for dedicated network builders to specific circumstances, we imply that these 'circumstances' have to be expressed in terms of the characteristics and dynamics of the particular STN we are dealing with. This suggests that the rather crude conceptual vocabulary we have developed so far needs further refinement. For instance, we have distinguished two types of actors - namely, dedicated network builders and critical actors. It is easy to see, however, that there are other important differences between the actors - for example, what could be 
called their 'strength'. It is clear that it is easier for a multi-billion dollar company to shape the course of technological development than it is for a local environmental group. We must therefore distinguish more types of actors, and we need to refine our concepts for characterizing book resilience and the role that technology plays in it. These steps should help us gain a better understanding of what kind of technologies are more or less likely 'to make it'.

In conclusion, we believe that the STN approach offers valuable suggestions for possible ways of guiding technological development on the basis of societal priorities. These, in their turn, indicate how the approach should be elaborated further. Thus, insights from the domain of technology studies promise to be of value in attempts to solve societal problems related to technological change. This encourages us to elaborate the STN approach further in our ongoing work.

- NOTES

We would like to acknowledge and thank Michel Callon, Phil Gummett, Andrew Moravcsik, Walter Vincenti and five anonymous referees for helpful comments.

1. See, for example, Arie Rip, Thomas J. Misa and Johan Schot, Managing Technology in Society: The Approach of Constructive Technology Assessment (London: Pinter, 1995).

2. One of us (Boelie Elzen) is attempting to do so in a research project with the title 'Towards Cleaner Cars and Transport', which is another joint research project between the universities of Nijmegen and Twente.

3. Readers interested in some general notions on how this might work in connection with military technology are referred to some of our earlier work. See, for example, B. Elzen, B. Enserink and W.A. Smit, 'Weapon Innovation: Networks and Guiding Principles', Science and Public Policy, Vol. 17, No. 3 (June 1990), 171-93; Annette Schaper, Wolfgang Liebert, Smit and Elzen, 'New Technological Developments and the Non Proliferation Regime - Re-directing and Constraining R\&D: The Case of Laser Fusion, Laser Isotope Separation and the Use of Highly Enriched Uranium', in Hans Günter Brauch, Henny J. van der Graaf, John Grin and Smit (eds), Controlling the Development and Spread of Military Technology: Lessons from the Past and Challenges for the 1990s (Amsterdam: Free University Press, 1992), 121-38.

4. The phrase 'Socio-Technical Network' has also been used by Stephen C. Zehr in his paper 'Method, Scale and Socio-Technical Networks: Problems of Standardization in Acid Rain, Ozone Depletion and Global Warming Research', Science 
Studies, Vol. 7, No. 1 (1994), 47-58. Zehr, however, uses the phrase in a generic sense, without any elaboration. In fact, he draws upon some insights from the actor-network approach.

5. See note 2.

6. See, for example, Boelie Elzen and Karel Mulder, 'What can Technology Assessment (not) learn from Technology Studies? An Analysis using Case Studies on Electric Vehicles and Biodegradable Plastics', paper for the Third International Conference on Advances in the Sociological and Economic Analysis of Technology (ASEAT), Manchester, 6-8 September 1995: originally published in Dutch, as 'Discussie paper Technology Assessement en Technologie Dynamica', in Jan van den Ende and Karel Mulder, Reader Summerschool Technology Assessment (Department of Technology Assessment, Delft University of Technology, August 1994), 3-36.

7. Bruno Latour, Science in Action (Milton Keynes, Bucks.: Open University Press, 1987); Michel Callon, 'The Sociology of an Actor-Network: The Case of the Electric Vehicle', in Callon, John Law and Arie Rip (eds), Mapping the Dynamics of Science and Technology: Sociology of Science in the Real World (New York, London \& Toronto: Macmillan, 1986), 19-34. To give an example in the military domain: air forces have had a long time monopoly on strategic bombing, and until World War II there was no indication that this would change. The development of missiles and rockets, however, changed things drastically.

8. See, for example, Thomas P. Hughes, Networks of Power: Electrification in Western Society, 1880-1930 (Baltimore, MD and London: Johns Hopkins University Press, 1983); Renate Mayntz and Hughes (eds), The Development of Large Technical Systems (Frankfurt am Main: Campus Verlag, 1988).

9. Trevor J. Pinch and Wiebe E. Bijker, 'The Social Construction of Facts and Artefacts: or How the Sociology of Science and the Sociology of Technology might Benefit Each Other', Social Studies of Science, Vol. 14 (1984), 399-441, esp. 42124.

10. Wiebe E. Bijker, 'The Social Construction of Bakelite: Towards a Theory of Invention', in Bijker, T.P. Hughes and T.J. Pinch (eds), The Social Construction of Technological Systems: New Directions in the Sociology and History of Technology (Cambridge, MA: MIT Press, 1987), 159-87.

11. In an earlier publication, we referred to these as 'underlying networks'. As this phrase suggests a hierarchy which was not intended, we have decided to use the new phrase 'pre-existing networks': see Elzen, Enserink \& Smit, op. cit. note 3.

12. Michel Callon, 'The Dynamics of Techno-Economic Networks', in Rod Coombs, Paolo Saviotti and Vivien Walsh (eds), Technological Change and Company Strategies (London: Harcourt Brace Jovanovich, 1992), 72-102.

13. See, for example, John Scott, 'Trend Report: Social Network Analysis', Sociology, Vol. 22, No. 1 (February 1988), 109-27.

14. This is not to say that technology cannot act - surely 'Chernobyl' acted when its core melted? But because the differences between humans and non-humans are relevant in the interventionist part of our approach (the second step), we should be able to account for these differences in the analytical part (the first step).

15. Callon, op. cit. note 12,74 .

16. Sometimes, intermediaries are simply 'passed on' - but, even then, processing has taken place to determine to whom it has been passed on. For 
example, politicians may decide to pass on taxpayers' money to the weapons labs. A different processing might have sent it to social security programmes.

17. See Boelie Elzen, Scientists and Rotors: The Development of Biochemical Ultracentrifuges (unpublished PhD dissertation, University of Twente, 1988), Chapter 7.

18. Thus, in the STN approach, the technology cannot be 'pin-pointed'. A different artefact is located with every actor in the network, and is 'reflected' in a variety of intermediaries sent out by her/him. In an extreme case, the only thing all those versions have in common may be its name. In the case of EFA, all actors would have ties with an EFA and act on the basis of that particular version. Nevertheless, there may be overlap in what characteristics of the artefact are considered important by different actors.

19. At the empirical level, of course, nothing is stable in any absolute sense. Human actors change (in terms of what they do and in terms of the networks they operate in), non-humans change (like technologies), interactions change. Stability, therefore, is something relative. Everything can change, but not everything can change (at least not drastically) at the same time.

20. We are even tempted to claim that perpetuating existing patterns of interaction is more important to the actors than the content of interaction, given that the content can reflect possibilities for continuing other interactions. The French stepping out of EFA (see below) might be a case in point, because choosing the British concept would have been threatening to certain French network relations. This perpetuation of existing patterns resembles the phenomena described by Giddens in his analyses of bureaucratization and institutionalization: see Anthony Giddens, The Constitution of Society: Outline of the Theory of Structuration (Berkeley, CA: University of California Press, 1984).

21. For an elaborate analysis of the role of expectations in technological development, see Harro van Lente, Promising Technology: The Dynamics of Expectations in Technological Development (Delft: Eburon, 1993).

22. The environment can be seen as consisting of a variety of other STNs. We will elaborate this when we discuss the role of 'pre-existing' networks.

23. Elzen, Enserink \& Smit, op. cit. note 3.

24. See, for example, Stockholm International Peace Research Institute, World Armaments and Disarmament: SIPRI Yearbook 1985 (London: Taylor \& Francis, 1985). Moreover, in Western Europe opposition grew against the American export restrictions on key technologies, which made advanced apparatus produced in Western Europe subject to prior American consent for intended exports.

25. To promote European cooperation on military technology, for instance, the governments of European NATO countries (including France) had, in 1984, revived the Independent European Programme Group (IEPG), an informal governmental consulting association: see, for example, SIPRI, op. cit. note 24, 237.

26. Their initiative resulted from their concern about the production termination of the Jaguar, Tornado and Harrier, while the British government had no firm plans for a next-generation aircraft. An excellent overview of the 'prehistory' of the European Aircraft has been given by Ivan Yates, Deputy Chief Executive [Engineering] of British Aerospace and Chairman of Eurofighter $\mathrm{GmbH}$, in a paper on 'Evolution of the New European Fighter; A British Industrial Perspective' (London: British Aerospace plc, 1988).

27. Anon., 'Europeans Agree on Future Fighter', Aviation Week \& Space 
Technology (2 January 1984), 17; Erhard Heckman, 'Jagdflugzeug 90 - eine Zwischenbilanz', Wehrtechnik, Jhrg.17, No. 10 (Oktober 1985), 16-23, esp. 16.

28. Heckman, ibid.; Anon., 'European Ministers Sign Pact To Study New Fighter Program', Aviation Week \& Space Technology (16 July 1984), 23.

29. Anon., ibid.; Anon., 'Armament Directors Refine EFA Options', Aviation Week \& Space Technology (28 May 1984), 18-20, esp. 19.

30 . The very active weapon export policy of France has brought this country into third place of the world list of arms-export countries, at a distance after the USA and the USSR: see SIPRI, SIPRI Yearbook 1989: World Armaments and Disarmament (Oxford: Oxford University Press, 1989), 199. See also Edward A. Kolodziej, Making and Marketing Arms: The French Experience and its Implications for the International System (Princeton, NJ: Princeton University Press, 1987).

31. Heckman, op. cit. note 27; Anon., op. cit. note 29, esp. 18.

32. David A. Brown, 'Britain Considering Flyoff To Choose Fighter Design', Aviation Week \& Space Technology (16 January 1984), 22-23, esp. 23.

33. The same argument made Spain and Italy incline to the British position.

34. Anon., op. cit. note 29 , esp. 18.

35. Heckman, op. cit. note 27, esp. 17.

36. Ivan Yates, Evolution of the New European Fighter; A British Industrial Perspective (London: British Aerospace plc, 1988), esp. 36.

37. David A. Brown, 'British Offer French Design Lead for Future Fighter Project', Aviation Week \& Space Technology (18 February, 1985), 16-17; Anon., 'British Firms Urge Fighter Policy', Aviation Week \& Space Technology (4 March 1985), 24.

38. Heckman, op. cit. note 27, esp. 17.

39. Anon., 'Europeans at Standstill on Fighter Project', Aviation Week \& Space Technology (18 March 1985), 294.

40. Anon., 'Europeans Fail to Agree on Fighter Project Issues', Aviation Week and Space Technology (27 May 1985), 27.

41. Anon., op. cit. note 29; esp. 18 .

42. Heckman, op. cit. note 27 , esp. 16 .

43. Heckman, ibid., esp. 17; Anon., 'Defense Ministers Order Another Report on EFA', Aviation Week \& Space Technology (24 June 1985), 21.

44. Heckman, op. cit. note 27, esp. 17-18.

45. Anon., 'Europeans Again Fail to Agree On Fighter as Deadline Nears', Aviation Week \& Space Technology (29 July 1985), 23; Heckman, op. cit. note 27, esp. 17-18.

46. Michael Feazel, 'Britain, Germany, Italy Agree To Build New European Fighter', Aviation Week \& Space Technology (12 August 1985), 22-24, esp. 22.

47. Heckman, op. cit. note 27, esp. 19-20; Anon., 'Spain Agrees to Join European Fighter Aircraft Program', Aviation Week \& Space Technology (9 September 1985), 20.

48. Jean-Paul Phillipe, 'Rafale on Course', Military Technology, Vol. 91, No. 8 (August 1991), 69-72, esp. 70.

49. Bijker, op. cit. note 10, 170-74; Wiebe E. Bijker, The Social Construction of Technology (unpublished PhD dissertation, University of Twente, 1990), 122-25.

50. Nick Cook, 'Radar Row Threatens to Cloud EFA's Progress', Jane's Defence Weekly, Vol. 11, No. 8 (25 February 1989), 316. 
51. Anon., 'Europeans Accept Fighter Design', Aviation Week \& Space Technology (26 May 1986), 28; Michael Feazel, 'Four Nations Form Consortium To Develop European Fighter', Aviation Week \& Space Technology (9 June 1986), 28; Frederick Bonnart, 'The European Fighter Aircraft: An Update', NATO's Sixteen Nations, Vol. 31, No. 7 (November 1986), 58-60, esp. 59.

52. Keith F. Mordoff, 'West Germany Releases Funds for EFA Development', Aviation Week \& Space Technology (28 September 1987), 26-27, esp. 27; Brian Wanstall, 'Eurojäger: Optimal für die Nato in Europa', Interavia, Vol. 43, No. 3 (March 1988), 249-51, esp. 249.

53. Anon., 'Thomson-CSF Discusses Baseline Radar for EFA', Aviation Week \& Space Technology (17 June 1985), 26.

54. Anon., 'EFA Radar Decision Hinges on New Technology, European Suppliers', Aviation Week \& Space Technology (4 August 1986), 157-59, esp. 159.

55. Ibid., 158.

56. Charles L. McKnett and Thomas H. Robinson, 'Developing a Radar for the EFA Project', Jane's Defence Weekly, Vol. 7, No. 7 (21 February 1987), 290-93, esp. 290.

57. Michael Feazel, 'Germans Take Conservative Approach in Planning for New Aircraft', Aviation Week \& Space Technology (23 June 1986), 61-69, esp. 61.

58. Cook, op. cit. note 50 .

59. Gregor Ferguson and Gerard Murphy, 'Aircraft Retrofit and Update', Defence Attaché, No. 3 (1987), 43-49, esp. 44.

60. To Spain, the MSD-2000 radar is attractive for similar reasons as for West Germany - namely, its commonality with the Hughes radar that will be installed in the McDonnell Douglas F-18s that Spain has bought.

61. The new signal processor would be highly flexible, allowing major updates with only software changes. Its development had been started by GEC three years before and had been company-funded: see Anon., 'EFA Radar Proposal May Include Improved Signal Processor', Aviation Week \& Space Technology (8 September 1986), 30.

62. Nick Cook, 'Eurofighter Radar and Engine Bids Set', Jane's Defence Weekly, Vol. 7, No. 1 (10 January 1987), 7.

63. William B. Scott, 'European Fighter Programs Spur Development Advanced Radars', Aviation Week \& Space Technology (13 July 1987), 145-54, esp. 147.

64. Guy Norris, 'Bordradarentwicklung - Im Schatten der Nimrod AEW', Interavia, Vol. 43, No. 2 (February 1988), 149-51, esp. 150.

65. The Eurofighter consortium itself became split along national lines. British Aerospace supported the ECR-90 submission on the grounds that it believed it to be technically superior, whereas the German MBB was backing the MSD-2000, because it offered a less risky approach to full-scale development: see Anon., 'Euro Partners Split over EFA Radar Choice', Jane's Defence Weekly, Vol. 10, No 17 (29 October 1988), 1043.

66. Nick Cook, 'W Germany Threatens Split over EFA Radar', Jane's Defence Weekly, Vol. 11, No. 7 (18 February 1989), 248.

67. The German Defence Ministry and the Luftwaffe (with backing from MBB) warned its EFA partners that it would install the enhanced AN/APG-65, already under development for the F-4 upgrading. The budget would be significantly overrun if two radars had to be developed and integrated separately into the EFA airframe. See Anon., 'Disagreement Between Britain, Germany Over Radar 
Could Threaten EFA's Future', Aviation Week \& Space Technology (20 February 1989), 21.

68. From an industry/technology point of view, the governments of Italy and Spain had hardly any preference, for no matter which radar project would be chosen, both FIAR and INISEL would participate in the development and production.

69. The Ministry of Defence in Bonn said that adoption of the ECR-90 would result in DM 300-500 m. in additional costs: see Nick Cook, 'UK, W Germany, Move to Defuse EFA Radar Row', Jane's Defence Weekly, Vol. 11, No. 9 (4 March 1989), 340; Anon., 'West Germany Causes New Concern over EFA', ibid, No. 26 (1 July), 1346.

70. Cook, op. cit. note 66 .

71. Ibid.

72. Cook, op. cit. note 69.

73. Nick Cook, 'USA Moves In on EFA Radar Split', Jane's Defence Weekly, Vol. 12, No. 3 (22 July 1989), 105.

74. In the meantime the UK Ministry of Defence was working on an optimization study of the MSD-2000 to see if it could be brought into line with the Royal Air Force's demanding radar requirement. AEG had prepared a study into the MSD2000 Plus which sought to ascertain whether the improved radar meets RAF requirements. See Anon., 'EFA Radar Bidders may Resubmit "Best Offers"', Jane's Defence Weekly, Vol. 12, No. 15 (14 October 1989), 759.

75. Anon., 'British Aerospace, Thomson-CSF Consider Making Joint Bid for Ferranti International Signal', Aviation Week \& Space Technology (16 October 1989), 32; Anon., 'GEC koopt voor $£ 310 \mathrm{mln}$ radar divisie Ferranti', NRCHandelsblad (24 januari 1990).

76. Another reason was to preserve Ferranti's technological know-how on radar: see David Saw, 'ECR-90: The Radar that Won the Battle', Military Technology, Vol. 34, No. 4 (April 1990), 31-33.

77. This was an important factor in overcoming the West German opposition while, at the same time, the British Ministry of Finance became less hesitant to guarantee a limited financial risk for West Germany: see Anon., 'Consortium Led by GEC Ferranti Defense Systems Awarded Contract to Develop ECR 90 Radar for EFA', Aviation Week \& Space Technology (14 May 1990), 31.

78. Ibid.

79. Anon., 'Helmut Kohl wil nog dit jaar naar Moskou', NRC-Handelsblad (11 januari 1990).

80. 'Defense as a means for preserving national sovereignty will not become superfluous' according to Schaffler, who referred to Sweden's national procurement programme 'which even includes the development of a new fighter aircraft'. Both Allison and Schaffer are quoted in Anon., 'EFA Partners Discuss Establishing Single Base for Training All Pilots' Aviation Week \& Space Technology (12 March 1990), 61.

81. Anon., 'Jäger 90 beleeft renaissance onder een andere naam', De Volkskrant (18 November 1992), 5.

82. So parliaments are nodal points in which very diverse issues can become connected to each other. This may vary across different nations. In France, for 
instance, there is very little parliamentary interference with matters of arms production and procurement.

83. Many examples of this can also be found in the development of the American B-1 bomber which we also studied: see Bert Enserink, Influencing Military Technological Innovation (Delft: Eburon, 1993); see also Elzen, Enserink \& Smit, op. cit. note 3 .

84. This example is taken from another research project in which one of us takes part: see, for example, Johan Schot, Remco Hoogma and Boelie Elzen, 'Strategies for Shifting Technological Systems: The Case of the Automobile System', Futures, Vol. 10, No. 10 (December 1994), 1060-76. In this paper, the analysis is not explicitly in STN terms, but the patterns described there could easily fit such an analysis.

85. Example taken from work on 'cleaner cars and transport': see previous note.

86. It is in this way that personal computers made typewriters obsolete in less than a decade.

Boelie Elzen works as an associate researcher at the University of Twente. He has published on issues of nuclear proliferation, assessment and dynamics of military technological developments, dynamics of supercomputing and the possibilities of developing and implementing cleaner alternatives to current modes of traffic and transport. His present interest is in elaborating the STN approach to the latter problem.

Address: Department of Philosophy of Science and Technology, Building TWRC, Room D310, University of Twente, PO Box 217, 7500 AE Enschede, The Netherlands. Fax: +3153 4894775; E-mail: b.elzen@wmw.utwente.nl

Bert Enserink is a Lecturer in Policy Analysis at the Department of Systems Engineering, Policy Analysis and Management (SEPA) at Delft University of Technology. His

research interests are in constructive technology assessment and participatory policy analysis; his current research topic is underground construction.

Address: Department of Systems Engineering, Policy Analysis and Management, Delft University of Technology, PO Box 5015, 2600 GA Delft, The Netherlands. Fax: +31 15 2783422; E-mail: berte@sepa.tudelft.nl Wim A. Smit is Associate Professor of Science, Technology and Society at the University of Twente. He has published on such issues as nuclear proliferation, assessment and dynamics of military technological developments, assessments of nuclear technology and risk assessments. 
Elzen, Enserink \& Smit: Socio-Technical Networks \& Change 141

His current interest is in socio-technical networks of military and dual-use technology.

Address: Department of Philosophy of Science and Technology, Building TWRC, Room D304, University of Twente, PO Box 217, 7500 AE Enschede, The Netherlands. Fax: +31 53 4894775; E-mail: w.a.smit@wmw.utwente.nl 